\title{
DISERTACIONES
}

ESTUDIOS

Anuario electrónico de estudios en Comunicación Social

ISSN: 1856-9536

Doi: dx.doi.org/10.12804/disertaciones.09.02.2016.07

Volumen 9, Número 2 / julio-diciembre 2016

Versión PDF para imprimir desde

http://revistas.urosario.edu.co/index.php/disertaciones

Para citar este artículo: Lozano, C., \& Gaitán, J. (2016). Vicisitudes de la investigación en comunicación en España en el sexenio 2009-2015. Anuario Electrónico de Estudios en Comunicación Social "Disertaciones”, 9(2), 139-162. Doi: dx.doi.org/10.12804/disertaciones.09.02.2016.07

\section{VICISITUDES DE LA INVESTIGACIÓN EN COMUNICACIÓN EN ESPAÑA EN EL SEXENIO 2009-2015}

\author{
Vicissitudes of Communication Research in Spain in the Sexennial \\ Period 2009-2015
}

Vicissitudes da investigação em comunicação na Espanha no sexénio 2009-2015

\author{
Lozano Ascencio, Carlos. Universidad Rey Juan Carlos (España) \\ carlos.lozano@urjc.es
}

Gaitán Moya, Juan Antonio. Universidad Complutense de Madrid (España)

jagamo@ucm.es

Fecha de recibido: 23 de octubre de 2015

Fecha de aprobado: 13 de abril de 2016

\section{RESUMEN}

La investigación en Comunicación en España es una actividad universitaria y profesional que tiene una aparente coherencia entre la formación académica de los investigadores, su capacitación metodológica y el tipo de aplicaciones profesionales con valor social y de mercado. En realidad, la investigación en Comunicación en España es una práctica social que sufre muchos desajustes que se reflejan en los temas, los procedimientos, destrezas metodológicas, creación de equipos, financiamiento y proyección social de las investigaciones. Este artículo resume los resultados de tres encuestas en línea realizadas por el grupo mDcs (Mediación Dialéctica de la Comunicación Social) en 2009, 2011 y 2013 a docentes, investigadores y profesionales de la comunicación en España. También se apoya en el actual proyecto de investigación I+D MapCom - que puede consultarse en su página web (www.mapcom.es - 


\title{
DISERTACIONES
}

ESTUDIOS

Anuario electrónico de estudios en Comunicación Social

ISSN: $1856-9536$

Doi: dx.doi.org/10.12804/disertaciones.09.02.2016.07

Volumen 9, Número 2 / julio-diciembre 2016

Versión PDF para imprimir desde

http://revistas.urosario.edu.co/index.php/disertaciones

Ref. CSO2013-47933-C4) -, centrado en el estudio del Sistema de la Investigación en España sobre prácticas sociales en comunicación: proyectos, grupos, líneas, objetos de estudio y métodos.

Palabras clave: investigación en comunicación, formación universitaria, aplicaciones sociales y de mercado.

\begin{abstract}
Communication research in Spain is a university and professional activity that has an apparent coherence between academic researchers, methodological training and the type of professional applications with social and market value. In fact, research in Communication in Spain is a social practice that suffers many imbalances that are reflected in the issues in the proceedings, in methodological skills in team building, lending and social projection of research . This article summarizes the results of three surveys online conducted by the group mDcs (Dialectic Mediation of Social Communication) in 2009, 2011 and 2013 to teachers, researchers and media professionals in Spain. It also builds on the current research project R \& D MapCom, available in http://www.mapcom.es/index.html (Ref. CSO2013-47933-C4) centered on the study of System Research Spain on social communication practices: Designing, Groups, Lines, study objects and methods.
\end{abstract}

Keywords: communication research, university education, social and market applications.

\section{RESUMO}

A investigação em Comunicação na Espanha é uma atividade universitária e profissional que tem uma aparente coerência entre formação acadêmica dos pesquisadores, a sua capacitação metodológica e o tipo de aplicações profissionais com valor social e de mercado. Na realidade, a investigação em Comunicação na Espanha é uma prática social que sofre muitos desajustes que se refletem nos temas, os procedimentos, destrezas metodológicas, criação de equipes, financiamento e projeção social das investigações. Este artigo resume os resultados de três enquetes online realizadas pelo grupo mDcs (Mediação Dialética da Comunicação Social) em 2009, 2011 e 2013 a docentes, pesquisadores e profissionais da comunicação na Espanha. Também se apoia no atual projeto de pesquisa I+D MapCom -que pode se consultar no seu site online (www.mapcom.es - Ref. CSO2013-47933-C4) -, centrado no estudo do Sistema da Investigação na Espanha sobre práticas sociais em comunicação: projetos, grupos, linhas, objetos de estudo e métodos.

Palavras-chave: investigação em comunicação, formação universitária, aplicações sociais e de mercado. 


\section{DISERTACIONES}

Estuolos

Anuario electrónico de estudios en Comunicación Social

ISSN: $1856-9536$

Doi: dx.doi.org/10.12804/disertaciones.09.02.2016.07

Volumen 9, Número 2 / julio-diciembre 2016

Versión PDF para imprimir desde

\section{Antecedentes}

La indagación sobre el estado de los estudios en comunicación y sobre la investigación existente en el mismo ámbito ha configurado una de las líneas de trabajo del Grupo mDcs (Mediación Dialéctica de la Comunicación Social). Este grupo interuniversitario se propuso trabajar en relación con la epistemología de la comunicación y, en particular, con la exploración del estatus de la comunicación como disciplina científica. Como indica Piñuel (2009), director del Grupo mDCs:

[...] el reconocimiento de la Teoría de la Comunicación como disciplina exige de la comunidad científica una teoría y una metodología unificada hábil, tanto para formular problemas y estrategias de investigación como para proporcionar un conocimiento de los aspectos relevantes al objeto de estudio y su aplicación a las prácticas humanas en las que la comunicación se hace presente.

Aunque la implantación de los estudios sobre la teoría de la comunicación, como disciplina académica, era una conquista que ya se había producido y resultaba incuestionable su consolidación institucional en múltiples universidades de todo el mundo, fueron los desarrollos del currículo formativo en esta materia los que se plantearon como los problemas de mayor relevancia, así como los relacionados con la investigación y los teóricos metodológicos, y relativos a la adecuación de sus aplicaciones en el análisis de los fenómenos comunicacionales.

Al poner en relación los componentes básicos que sustentan la investigación de la comunicación en España (figura 1), es decir, la formación universitaria de los investigadores y su capacitación para la investigación efectiva en comunicación, dentro y fuera del ámbito universitario, cabía presuponer que existieran tantas concordancias, causas y efectos, equilibrios y compensaciones como podría suceder en cualquier otro ámbito de la investigación social.

Figura 1. Aparente simetría y coherencia de los componentes que sustentan la investigación de la Comunicación en España

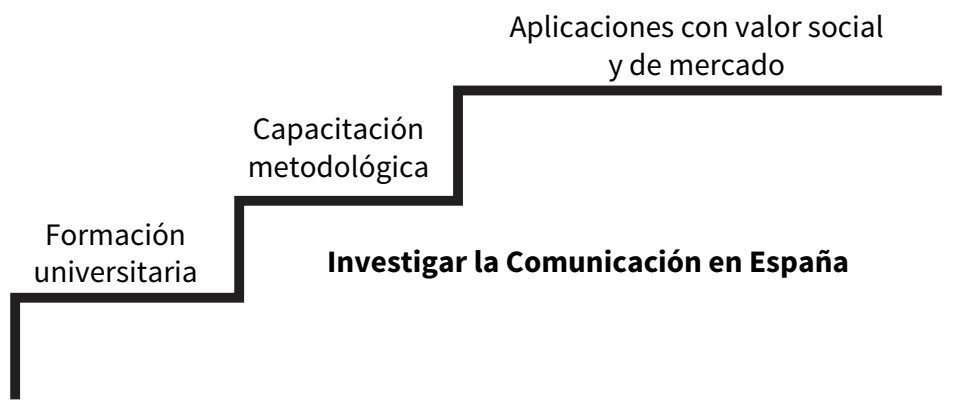

Sin embargo, en este artículo, se van a desentrañar algunas claves que explican el estado de la investigación de la comunicación en España, al poner en cuestión esta pretendida armonía de los componentes que la sustentan. Es decir, siguiendo la figura 1, que simula una escalera construida con solidez y coherencia (cuyos escalones abarcan desde los aspectos más básicos de la formación hasta el empleo profesional de técnicas y conocimientos 


\section{DISERTACIONES}

Estudios

Anuario electrónico de estudios en Comunicación Social

ISSN: $1856-9536$

Doi: dx.doi.org/10.12804/disertaciones.09.02.2016.07

Volumen 9, Número 2 / julio-diciembre 2016

Versión PDF para imprimir desde

en proyectos con valor social y de mercado), se planteará qué desajustes podrían dificultar el ascenso por esos escalones de la investigación de la Comunicación.

En esta línea, se formularon varias hipótesis con el objeto de confrontar las variables de la docencia y de la investigación universitaria en Comunicación, así como las propias de la investigación universitaria y las de la investigación social y de mercado. Así se trataba de contrastar:

- La formación curricular universitaria en el ámbito de la Comunicación frente a la investigación comunicacional en el marco universitario.

- La capacitación metodológica de los investigadores (universitarios o no) frente a la competencia requerida en la investigación comunicacional (dentro o fuera de la universidad).

- Las diferencias y semejanzas existentes entre la investigación comunicacional producida en la universidad y la investigación social y de mercado no universitarias.

En concreto, en este artículo se va a tratar de hacer un balance y discusión de los resultados obtenidos en las tres encuestas en línea que se llevaron a cabo siguiendo esta línea de investigación, al poner centro en los resultados del contraste de las variables mencionadas. Las encuestas fueron las siguientes:

- Encuesta sobre la docencia en teoría de la comunicación/información en España, resto de Europa y América Latina (2009).

- Encuesta sobre la investigación en comunicación en el ámbito universitario español (2011).

- Encuesta sobre la investigación en comunicación el ámbito social y de mercado español (2013).

La información proporcionada por cada una de estas encuestas constituyó el preámbulo necesario para la realización de cuatro simposios internacionales bianuales, donde se difundieron los datos obtenidos sobre el estado de la cuestión del tema investigado. Siempre en colaboración con la sección temática de Teorías y Métodos de Investigación en Comunicación, de la AE-IC (Asociación Española de Investigadores de la Comunicación), tales simposios han servido también para promover el debate sobre políticas de investigación y sobre metodologías de investigación en Comunicación. A saber, 2009: Simposio internacional de innovación educativa en el espacio europeo y latinoamericano, Universidad Complutense Madrid; 2011: Investigar la comunicación en España, $1 .{ }^{\text {er }}$ simposio nacional de grupos de investigación, Universidad Rey Juan Carlos; 2013: Simposio internacional sobre política científica en comunicación, Universidad de Valladolid, campus de Segovia; y 2015: Simposio del mapa de la investigación en España sobre prácticas sociales en Comunicación, Universidad de Málaga.

Y, como último hito del progreso alcanzado por esta línea de investigación, cabe mencionar la I+D+i, que se desarrolla en la actualidad, titulada El sistema de investigación en España sobre prácticas sociales de comunicación. Mapa de proyectos, grupos, líneas, objetos de estudio y métodos (CSO2013-47933-C4-1-P). Esta investigación en curso, está auspiciada tanto por la AE-IC como por Asociaciones internacionales de Investigación en Comunicación (COMO ECREA, y AIERI) en calidad de EPO's, y su diseño comprende cuatro equipos coordinados en todo el territorio español bajo la dirección de José Luis Piñuel.

\section{Metodología}

El universo finito de docentes, investigadores y profesionales que responden a los cuestionarios de las tres encuestas en línea señaladas constituye una muestra exenta de representatividad estadística, pero elaborada con un 


\section{DISERTACIONES}

ESTUDIOS

Anuario electrónico de estudios en Comunicación Socia

ISSN: 1856-9536

Doi: dx.doi.org/10.12804/disertaciones.09.02.2016.07

Volumen 9, Número 2 / julio-diciembre 2016

Versión PDF para imprimir desde

http://revistas.urosario.edu.co/index.php/disertaciones

propósito heurístico, de forma que se ha podido constituir en un conjunto de casos de significatividad estructural, muy pertinente para perfeccionar metodologías y posibilitar la formulación de nuevas hipótesis que han permitido abrir futuras investigaciones y encuentros entre expertos en la materia, como los simposios ya mencionados más arriba.

Hay que decir que la primera encuesta en línea está dirigida a los docentes españoles, europeos y latinoamericanos ${ }^{1}$, quienes centran sus esfuerzos didácticos (intereses, métodos, experiencias) en torno a las Teorías de la Comunicación ${ }^{2}$. La encuesta se realizó por medio de Internet, controlando el acceso al cuestionario mediante correos electrónicos previos de invitación a todas aquellas personas que, finalmente, formaron parte de la base de datos. A la encuesta en línea respondieron 99 profesores españoles, el 27,3\% del total de encuestados de 237 universidades de Europa y América Latina en la que se involucran más de 40 países. Con esta iniciativa, se han podido configurar los principales perfiles de la enseñanza de las teorías de la Comunicación/Información en las universidades españolas. La encuesta permite elucidar los desajustes entre la docencia que se imparte y la investigación que se está llevando a cabo en este ámbito de estudios.

En la segunda encuesta en línea se interroga a profesores investigadores españoles (de los que el $36 \%$ son investigadores principales, IP) de 30 universidades donde se investiga en el campo de la Comunicación en España ${ }^{3}$. La encuesta posibilita descubrir los principales desajustes existentes entre la capacitación metodológica que poseen los investigadores y la competencia requerida en la investigación comunicacional en el ámbito universitario español.

En la tercera encuesta en línea se les pregunta a responsables de la investigación de 32 entidades (corporaciones, consultoras e institutos de investigación, fundaciones, medios de comunicación y onG). Esta última encuesta procura información suficiente acerca de los desajustes entre la capacitación metodológica que poseen los investigadores y la competencia requerida en la investigación comunicacional en España fuera de la universidad, en el ámbito social y de mercado.

1 Por supuesto, para el propósito de este artículo, se han considerado sólo los resultados relativos a los docentes españoles que imparten docencia de asignaturas de teoría y metodología sobre la materia de Comunicación/Información y que, además, son investigadores en el marco de las Facultades de Ciencias de la Información/Comunicación en España. Para las tres primeras encuestas, esta es la población de referencia, pero no se realiza un muestreo probabilístico porque se trata de estudios exploratorios con un propósito heurístico, sin ánimo de representatividad. La estrategia investigadora es cualitativa y trata de recoger la percepción de los profesores-investigadores como informantes. En las encuestas en línea se tienen en cuenta sólo las respuestas obtenidas como casos clínicos, que pueden ofrecer, por tanto, una visión indicativa y estratégica del objeto de estudio de esta investigación.

2 Como se sabe, la teoría de la Comunicación/Información es materia troncal en todas las carreras de las Facultades de cc de la Información/Comunicación, además, interesan en este estudio los docentes en métodos de investigación en comunicación en tanto que investigadores sobre este objeto. Lozano y Vicente (2010). Consúltese también Lozano (2010). Los diseños de las asignaturas universitarias relacionadas con las teorías de la comunicación en las principales universidades europeas. Asimismo, Lozano y Gaitán (2011).

3 Cfr. el corpus en Lozano (2014) y en Gaitán (2014). 


\section{DISERTACIONES}

Estudios

Anuario electrónico de estudios en Comunicación Social

ISSN: 1856-9536

Doi: dx.doi.org/10.12804/disertaciones.09.02.2016.07

Volumen 9, Número 2 / julio-diciembre 2016

Versión PDF para imprimir desde

El valor heurístico de estas investigaciones puede confrontarse en los Congresos de la AE-IC, donde han ido presentándose y debatiéndose sus avances y, finalmente, en el proyecto I+D que está en curso de realización, el denominado MapCom (2007-2013), proyecto culminante de esta línea de investigación. Estos estudios exploratorios previos proporcionaron la información suficiente (junto con los debates en los congresos de AE-IC) para la elaboración de los ítems del estudio final (MapCom).

\section{Resultados}

\subsection{Los temas de los docentes y de los investigadores universitarios}

¿Qué es lo que más se suele investigar? La encuesta en línea sobre la docencia proporcionó datos que hacían pensar que los programas docentes no siempre se ajustaban a los fenómenos comunicacionales que tanta importancia estaban adquiriendo en la primera década del nuevo milenio, con el uso globalizado de la red de Internet y de los diversos dispositivos y avances tecnológicos que estaban suponiendo las TIC's en la vida cotidiana. Por supuesto, esta realidad ha cambiado en gran medida desde entonces (2009), como puede comprobarse con la mera supervisión de los últimos planes de estudio y la irrupción de los másteres especializados en los fenómenos comunicacionales más recientes, pero, a la sazón, según los datos que suministraron los propios profesores de comunicación, muchos de ellos investigadores, no parecía que se hubiera integrado el cambio ocurrido en las prácticas comunicacionales en las aulas y en los laboratorios universitarios en los que se impartían materias sobre comunicación. Con este panorama general de impasse en el estado de la enseñanza universitaria de la comunicación, supusimos que no guardaría una relación especular con la investigación que se estaba realizando en el mismo tiempo.

Tabla 1. La docencia de las teorías de la comunicación en España (2009)

\begin{tabular}{|l|l|c|}
\hline \multirow{5}{*}{ Teorías y modelos predominantes } & Sin teorías y modelos predominantes & $50 \%$ \\
\cline { 2 - 3 } & Teorías y modelos críticos & $20 \%$ \\
\cline { 2 - 3 } & $\begin{array}{l}\text { Algunas teorías y modelos: constructivistas, sistémicos, } \\
\text { funcionalistas, estructuralista o informacionales }\end{array}$ & $30 \%$ \\
\hline \multirow{5}{*}{ Paradigmas disciplinares dominantes } & Interdisciplinariedad & $50 \%$ \\
\cline { 2 - 3 } & Paradigma sociológico & $17 \%$ \\
\cline { 2 - 3 } & Paradigma psicológico y de la psicología social & $17 \%$ \\
\cline { 2 - 3 } & Otros paradigmas: lingüístico/semiótico, histórico, etc. & $17 \%$ \\
\hline \multirow{5}{*}{ Objetos predominantes en la formación } & Comunicación de masas & $70 \%$ \\
\cline { 2 - 3 } & Comunicación organizacional y comunicación interpersonal & $16 \%$ \\
\cline { 2 - 3 } & Comunicación grupal, Educomunicación... & $14 \%$ \\
\hline
\end{tabular}




\section{DISERTACIONES}

Estudios

Anuario electrónico de estudios en Comunicación Social

ISSN: 1856-9536

Doi: dx.doi.org/10.12804/disertaciones.09.02.2016.07

Volumen 9, Número 2 / julio-diciembre 2016

Versión PDF para imprimir desde

http://revistas.urosario.edu.co/index.php/disertaciones

En concreto, en la investigación sobre la docencia universitaria (tabla 1)4, se había comprobado que esta se encontraba un tanto ordenada a la enseñanza de las teorías, modelos y métodos que, en la mayor parte de los casos provenían de otras disciplinas sociales y humanas, y que eran adoptados para estudiar la historia de la investigación en la comunicación de masas, antes que centrada en otros objetos como la Comunicación corporativa, la Comunicación interpersonal, etc. Se entendió así que la hipótesis sobre el desajuste entre la docencia y la investigación en el campo era una hipótesis plausible. En la encuesta de 2011 sobre la investigación universitaria en el ámbito de la Comunicación, la falta de concordancia de los temas elegidos para la investigación realizada por los profesores universitarios en relación con los elegidos para la enseñanza universitaria constituía un fiel exponente de cómo muchas de las materias de los antiguos planes de estudio se seguían aplicando: sobre todo centrados en tópicos como los medios de comunicación de masas y la práctica periodística, etc., mientras que los contenidos justificados como formativos (históricos, metodológicos, etc.) no siempre estaban adaptados a las características peculiares de los nuevos fenómenos comunicacionales.

Como se observa en la tabla $2^{5}$, la corroboración de la hipótesis del desajuste entre la docencia y la investigación universitarias se aprecia en la desigual distribución de la dominancia de los objetos de estudios, extremo que, sin embargo, no se aprecia en la comunicación de masas que sigue siendo objeto de estudio predominante tanto en la formación de los alumnos de teorías de la comunicación como en las preferencias de investigación de los profesores universitarios que imparten esta asignatura.

Tabla 2. Objetos de estudio dominantes en la investigación universitaria (2011)

\begin{tabular}{|l|c|}
\hline $\mathrm{NP} / \mathrm{NC}$ & $43,8 \%$ \\
\hline Comunicación de masas & $41,9 \%$ \\
\hline Comunicación organizacional & $7,6 \%$ \\
\hline Otras & $3,8 \%$ \\
\hline Comunicación educativa & $1,0 \%$ \\
\hline Comunicación grupal & $1,0 \%$ \\
\hline Comunicación interpersonal & $1,0 \%$ \\
\hline Total & $100,0 \%$ \\
\hline
\end{tabular}

4 La fundamentación teórica y metodológica de las variables y categorías de análisis de los proyectos citados en este artículo pueden encontrarse en Piñuel y Lozano (2006), también en Gaitán y Piñuel (1995) y en Gaitán y Piñuel (1998).

5 A partir de esta tabla, los porcentajes sobre los NP/NC han de comprenderse de acuerdo con la índole cualitativa de los datos, de modo que estos constituyen las ausencias voluntarias de respuesta de los participantes, que libremente opinan o dejan de opinar sobre lo que quieren o saben, porque las alternativas de respuesta adoptadas en el formato en línea no son cerradas. Por esta razón, dada esa índole cualitativa de la investigación, no cabe entender que las respuestas contenidas en esta tabla avalen la interdisciplinariedad de los estudios sobre Comunicación o sean una demostración de la carencia de una disciplina propia, pero, en cambio sí podrían interpretarse como un dato indicativo en este sentido, es decir como una hipótesis, nunca como una conclusión. 


\section{DISERTACIONES}

Estuolos

Anuario electrónico de estudios en Comunicación Social

ISSN: 1856-9536

Doi: dx.doi.org/10.12804/disertaciones.09.02.2016.07

Volumen 9, Número 2 / julio-diciembre 2016

Versión PDF para imprimir desde

http://revistas.urosario.edu.co/index.php/disertaciones

\subsection{Los temas de los investigadores externos a la universidad}

¿Qué es lo que suelen investigar más las agencias consultoras y los gabinetes de investigación de las empresas españolas? En primer lugar, están los temas más recurrentes que, según 2 de cada 3 investigadores consultados, tienen que ver con la investigación corporativa a propósito de la imagen, la creación de identidad, la reputación y el posicionamiento de las marcas. En este ámbito, también destacan $(47,3 \%)$ los temas que analizan las estrategias de comunicación en relación con la prospectiva y a la organización de eventos. Un porcentaje muy similar de encuestados ( 2 de cada 3 ) reconoce que el marketing de productos y/o de servicios es el otro ámbito temático fundamental para desarrollar sus investigaciones. En esta área de la investigación de mercado destaca también $(47,3 \%)$ los temas que tienen que ver directamente con la publicidad.

Tabla 3. Temas dominantes en la investigación social y de mercado

\begin{tabular}{|l|c|}
\hline $\begin{array}{l}\text { Investigación de Mercado } \\
\text { (marketing de productos y/o servicios, publicidad, patrocinio, } \\
\text { mecenazgo y marketing social de servicios) }\end{array}$ & $58,2 \%$ \\
\hline $\begin{array}{l}\text { Comunicación Social y Política } \\
\text { (Com. de instituciones ciudadanas, lobby político y empresarial, } \\
\text { Comunicación política y electoral, Responsabilidad social } \\
\text { corporativa y RSE }\end{array}$ & $9,1 \%$ \\
\hline $\begin{array}{l}\text { Comunicación corporativa } \\
\text { Imagen, creación de identidad, reputación y posicionamiento de } \\
\text { las marcas, estrategias de comunicación, prospectiva y eventos. }\end{array}$ & $3,6 \%$ \\
\hline $\begin{array}{l}\text { Comunicación de Medios. } \\
\text { Audiencias, Clipping, Auditorias de medios. }\end{array}$ & $1,8 \%$ \\
\hline No responde & $27,3 \%$ \\
\hline Total & $100,0 \%$ \\
\hline
\end{tabular}

En segundo lugar están los temas de investigación en comunicación menos frecuentes que, según 1 de cada 3 investigadores, es el estudio de la comunicación en las instituciones ciudadanas (asociaciones, sindicatos, ong, colegios profesionales, etc.) y 1 de cada 4 investigadores encuestados sostiene que es la Responsabilidad Social Corporativa (RSC), los estudios de audiencias de medios y el patrocinio, mecenazgo y marketing social de servicios. En tercer lugar, están los temas que menos suelen aparecer en las investigaciones que, según reconocen 1 de cada 10 encuestados, son lobby político y empresarial, comunicación de crisis y/o litigios, auditoria de medios, clipping y visibilidad mediática.

Los temas que están relacionados con el área de la investigación de mercado (marketing de productos y/o servicios, publicidad, patrocinio, mecenazgo y marketing social de servicios) son los más demandados por los clientes (según el $80 \%$ de los encuestados); y de hecho casi ese mismo porcentaje de investigadores (76,32\%) reconoce que las investigaciones de mercado son las que aportan mayor rentabilidad. Por otra parte, la investigación corporativa y los temas relacionados con esta(imagen, creación de identidad, reputación y posicionamiento de las marcas, estrategias de comunicación prospectiva y eventos), a pesar de ser uno de los temas más utilizados por los investigadores de la comunicación con valor de mercado, es muy poco demandado por los clientes y, por 


\section{DISERTACIONES}

ESTUDIOS

Anuario electrónico de estudios en Comunicación Social

ISSN: 1856-9536

Doi: dx.doi.org/10.12804/disertaciones.09.02.2016.07

Volumen 9, Número 2 / julio-diciembre 2016

Versión PDF para imprimir desde

http://revistas.urosario.edu.co/index.php/disertaciones

supuesto, apenas es un tema rentable. Esta aparente contradicción (dedicarle muchos esfuerzos a un área poco demandada y nada rentable), solo se explica si se tiene en cuenta que la gestión de la imagen ha adquirido una enorme relevancia para las empresas modernas, lo que la convierte en un instrumento de diferenciación y de obtención de ventajas.

Las empresas cuidan sobremanera su imagen (marca), ya que es más duradera y resistente que los productos o servicios que ofrecen. Al consultar por los objetivos dominantes de la actividad investigadora (figura 2), casi la mitad de los que responden a esta pregunta reconocen que las principales motivaciones que conducen los temas de sus indagaciones tienen que ver más bien con la planificación (43,2\%) que con la evaluación (27\%).

\section{Figura 2. Principal objetivo de la actividad investigadora}

Intervención en la sociedad o el mercado y medición de efectos

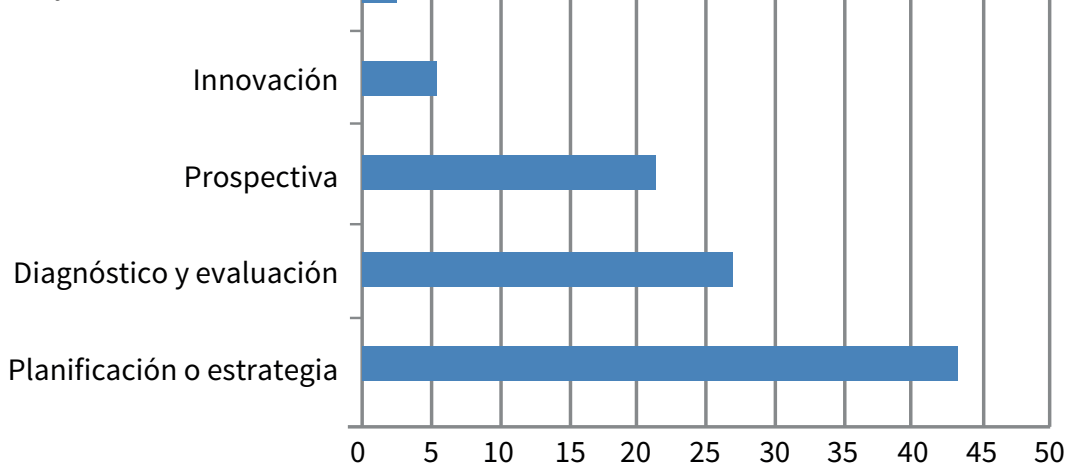

En la figura 3 puede comprobarse la diversa formación de los investigadores de la comunicación en la universidad y en la empresa. La investigación social y de mercado en comunicación se realiza aún con predominancia de profesionales cuya formación es sociológica (30\% aprox.), antes que de otras disciplinas (estudios en comunicación, psicología, empresariales y otros). En cambio, la investigación que se realiza en el marco universitario sobre comunicación está provista de forma casi única (80\% aprox.) por egresados de las facultades de ciencias de la información y de la comunicación, siendo irrelevantes el resto de procedencias.

En consecuencia, cabe decir que la especialización en el ámbito comunicacional de la investigación ha llegado antes a la universidad que al mercado, donde aún se nutre de profesionales de diversa formación generalista en las ciencias sociales. 


\section{DISERTACIONES}

ESTUDIOS

Anuario electrónico de estudios en Comunicación Social

ISSN: 1856-9536

Doi: dx.doi.org/10.12804/disertaciones.09.02.2016.07

Volumen 9, Número 2 / julio-diciembre 2016

Versión PDF para imprimir desde

http://revistas.urosario.edu.co/index.php/disertaciones

Figura 3. La diversa formación de los investigadores

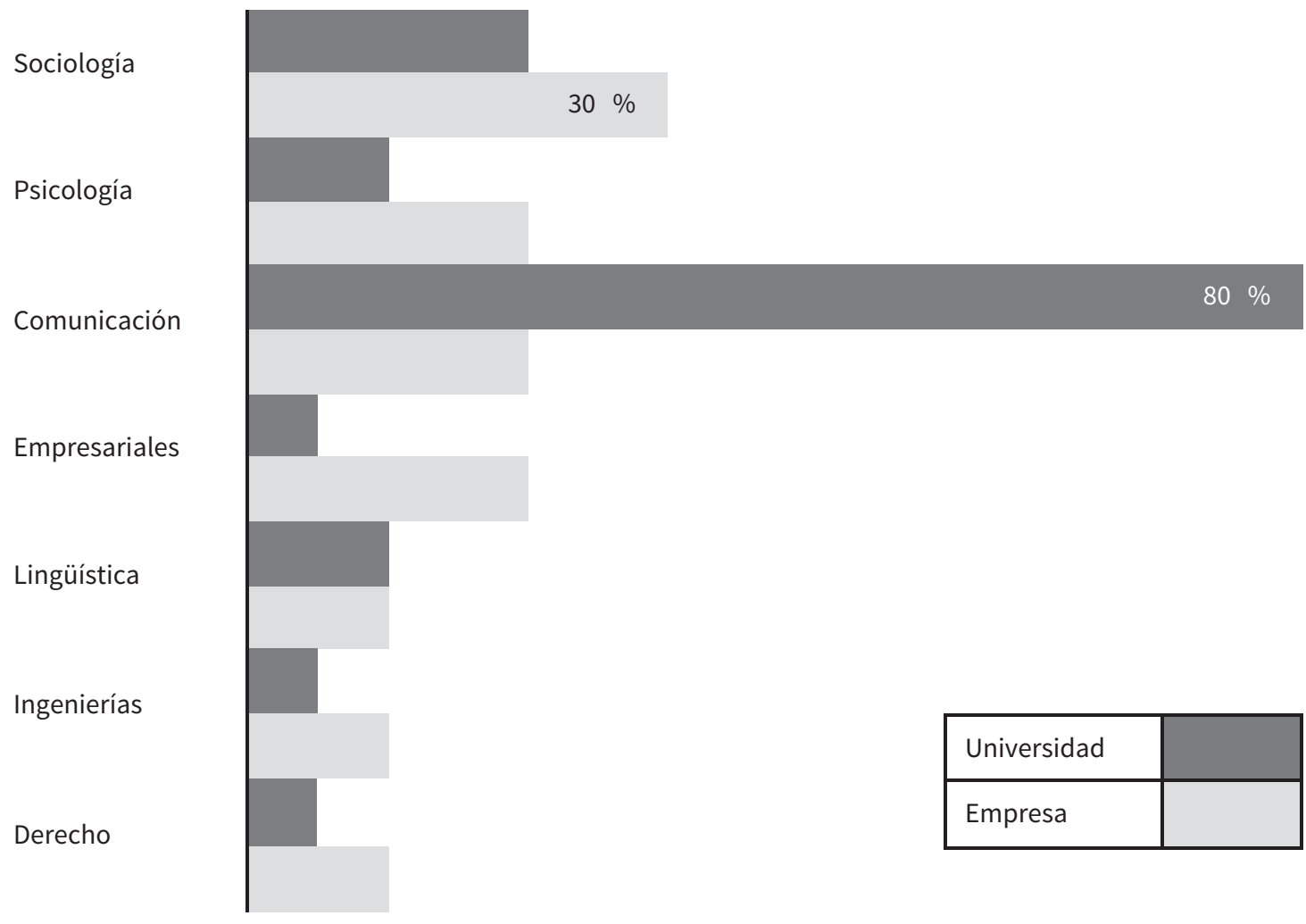

\subsection{Los procedimientos de la investigación}

¿Cómo se investiga? Para evaluar los desajustes que relacionan la formación con la eficiencia en la investigación de la comunicación fuera y dentro de la universidad, conviene considerar, en primer lugar, el campo metodológico en que se desarrolla, así como las estrategias metodológicas y las técnicas e instrumentos más utilizados en la investigación

\subsubsection{Los marcos metodológicos de campo y de gabinete}

El marco metodológico en el que se desarrolla la investigación sobre comunicación converge para ambos sectores en la investigación de campo. No obstante, hay que reparar en una mayor distribución de los marcos metodológicos en la investigación universitaria. En esta, si bien la investigación de campo es mayoritaria (56\%), también puede observarse un uso no desdeñable (39\% aprox.) de marcos metodológicos de gabinete, propios de los estudios documentales.

Por otro lado, en los estudios sociales y de mercado en comunicación resulta ser la investigación de campo la que impera (78\%), siendo el resto de marcos de la investigación prácticamente inexistentes, lo cual se relaciona con el abrumador uso en este último tipo de investigación de la técnica de encuesta que requiere el uso constante del alquiler o gestión de redes de campo o de paneles para administrar los cuestionarios, ya sea de forma coyuntural o longitudinal. 


\section{DISERTACIONES}

ESTUDIOS

Anuario electrónico de estudios en Comunicación Social ISSN: $1856-9536$

Doi: dx.doi.org/10.12804/disertaciones.09.02.2016.07

Volumen 9, Número 2 / julio-diciembre 2016

Versión PDF para imprimir desde

http://revistas.urosario.edu.co/index.php/disertaciones

Tabla 4. Campo metodológico de la investigación

\begin{tabular}{|l|c|c|c|c|}
\hline \multirow{2}{*}{} & \multicolumn{2}{|c|}{ Universidad } & \multicolumn{2}{c|}{ Sociedad y mercado } \\
\cline { 2 - 5 } & Frec. & $\%$ & Frec. & $\%$ \\
\hline Investigación de campo & 150 & 56 & 29 & 78 \\
\hline Investigación de laboratorio & 12 & 5 & 4 & 11 \\
\hline Investigación documental o de gabinete & 104 & 39 & 4 & 11 \\
\hline Respuestas Totales & 266 & 100 & 37 & 100 \\
\hline
\end{tabular}

\subsubsection{Uso convergente de técnicas y herramientas}

En conjunto, predomina el uso de las técnicas de investigación mixtas, que articulan técnicas cuantitativas y cualitativas, para analizar los distintos objetos de estudio comunicacionales. Ahora bien, si hubiera que destacar las técnicas más empleadas, en la universidad se imponen las de índole cualitativa del tipo de las técnicas de análisis del discurso y, en cambio, en la investigación social y de mercado prevalecen las cuantitativas de la mano de la técnica de encuesta. Esto es un dato relativo al análisis del discurso no al análisis de contenido, que es la técnica cuantitativa más frecuentada por los docentes investigadores de la academia. Por lo tanto, solo en la comparación con la investigación realizada fuera de la universidad, tiene sentido el anterior aserto ${ }^{6}$.

Se explica así que, quizás por su polivalencia, la herramienta más ampliamente extendida sea el programa estadístico informático SPSS, muy usado para estudiar la comunicación de masas y muy frecuentado en los estudios de mercado, así también cabe destacar el uso de la hoja de cálculo de Excel.

Tabla 5. Técnicas de investigación

\begin{tabular}{|l|c|c|c|c|}
\hline & \multicolumn{2}{|c|}{ Universidad } & \multicolumn{2}{c|}{ Sociedad y mercado } \\
\cline { 2 - 5 } & Frec. & $\%$ & Frec. & $\%$ \\
\hline Análisis de contenido, del discurso y documental & 125 & 43 & 3 & 5 \\
\hline Conversación con individuos / grupos & 68 & 24 & 7 & 13 \\
\hline Encuesta & 42 & 15 & 26 & 47 \\
\hline Observación & 40 & 14 & 18 & 33 \\
\hline Experimentación & 12 & 4 & 1 & 2 \\
\hline Respuestas Totales & 287 & 100 & 55 & 100 \\
\hline
\end{tabular}

6 Por supuesto, las investigaciones sobre comunicación que son referidas en las revistas especializadas no están contempladas aquí, pues en estas se produce un sesgo de criterio de los editores, que privilegia la publicación de los estudios empíricos cuantitativos sobre los teóricos y cualitativos, y que no abarca el conjunto de estudios de la investigación universitaria (más diversos en cuanto a presupuestos epistemológicos, teóricos y metodológicos), como denuncian los propios profesores investigadores consultados en esta investigación. 


\section{DISERTACIONES}

ESTUDIOS

Anuario electrónico de estudios en Comunicación Social

ISSN: $1856-9536$

Doi: dx.doi.org/10.12804/disertaciones.09.02.2016.07

Volumen 9, Número 2 / julio-diciembre 2016

Versión PDF para imprimir desde

http://revistas.urosario.edu.co/index.php/disertaciones

\subsubsection{Controles, prescripciones y dudas acerca de las garantías metodológicas}

Como se observa en la tabla 6 , en la investigación social y de mercado de la comunicación predomina el control sobre la fiabilidad de las técnicas utilizadas antes que la validez de los métodos o la falsación teórica, prácticamente excluida. Frente a esta realidad, la investigación universitaria de la comunicación distribuye más los controles y asegura más las garantías metodológicas sobre todo respecto a teorías y técnicas.

A diferencia de lo que suele ocurrir con la investigación que se desarrolla en el ámbito universitario (en la que los controles metodológicos son prescriptivos: ser o no ser de su carácter científico), la investigación social y de mercado presenta para los mismos autores de este sector una evaluación dispar en la que las teorías se falsan algunas veces o nunca el $43 \%$ de las veces, aproximadamente, los métodos no se validan o solo se validan algunas veces en torno al $30 \%$ y las técnicas ofrecen dudas, en el sentido de que no se someten a controles de fiabilidad o solo lo hacen en ciertos casos en un $20 \%$. Por decirlo de otro modo, las garantías que ofrece la práctica investigadora para los mismos investigadores que realizan los estudios sociales y de mercado en este campo resulta ser bastante limitada: solo se somete a los controles de calidad elevados o muy elevados el $45 \%$ del total de los trabajos. Esta autoevaluación tan crítica que realizan los investigadores no universitarios sobre las garantías metodológicas de su investigación comunicacional se une a la percepción de sus carencias principales que, como aquí se ha indicado, se relacionan con su apreciación acerca de la necesidad de investigadores provenientes del ámbito universitario que cuenten con una buena formación metodológica y técnica, caracterizada por su capacidad analítica y la actualización de conocimientos.

Tabla 6. La investigación sometida a garantías metodológicas

\begin{tabular}{|l|c|c|c|c|}
\hline \multirow{2}{*}{} & \multicolumn{2}{|c|}{ Universidad } & \multicolumn{2}{c|}{ Sociedad y mercado } \\
\cline { 2 - 5 } & Frec. & $\%$ & Frec. & $\%$ \\
\hline Falsación teorías & 146 & 29 & 6 & 15 \\
\hline Validez métodos & 129 & 26 & 15 & 38 \\
\hline Fiabilidad técnicas & 220 & 45 & 19 & 47 \\
\hline Respuestas Totales & 495 & 100 & 40 & 100 \\
\hline
\end{tabular}

\subsection{Vicisitudes entre la investigación universitaria y la investigación social y de mercado a propósito de la comunicación}

\subsubsection{La Asociación Española de Investigación en Comunicación (AE-IC)}

Es sabido que el mundo académico de la investigación en comunicación se regula por asociaciones especializadas que marcan tendencias y preferencias temáticas. En la actualidad la AE-IC (Asociación Española de Investigación

7 En España han sido varias las asociaciones que han existido. Tan solo se mencionan las más importantes: Asociación para la Investigación de la Comunicación (AIC) 1982. Asociación de Investigadores en Comunicación del Estado Español (AIEC) 1983. Societat Catalana de Comunicació del Institut d'Estudis Catalans 


\section{DISERTACIONES}

ESTUDIOS

Anuario electrónico de estudios en Comunicación Social

ISSN: $1856-9536$

Doi: dx.doi.org/10.12804/disertaciones.09.02.2016.07

Volumen 9, Número 2 / julio-diciembre 2016

Versión PDF para imprimir desde

http://revistas.urosario.edu.co/index.php/disertaciones

en Comunicación) es la principal asociación española en comunicación desde 2008. Cuenta con siete secciones temáticas que organizan el campo de la investigación por temas.

- Comunicación Estratégica y Organizacional.

- Comunicación y Cultura Digital.

- Estructura y Políticas de la Comunicación.

- Estudios de Audiencia y Recepción.

- Estudios sobre el Discurso.

- Producción y Circulación de Contenidos.

- Teorías y Métodos de Investigación en Comunicación.

En comparación con otras asociaciones como IAMCR (International Association for Media and Communication Research), ALAIC (Asociación Latinoamericana de los investigadores de la Comunicación), ECREA (European Communication Research and Education Association), e ICA (International Communication Association) tiene muchas menos secciones temáticas en su estructura, no obstante, al preguntar a los investigadores por una valoración sobre la forma en que se organiza temáticamente la investigación, 1 de cada 3 encuestados $(30,4 \%)$ considera que dicha distribución temática es bastante o muy pertinente (tabla 7).

Tabla 7. Valoración de la principal Asociación Nacional en Comunicación (AE-IC)

\begin{tabular}{|l|c|c|}
\hline & Frec. & $\%$ \\
\hline NP/NC & 60 & $57,1 \%$ \\
\hline Bastante pertinente & 20 & $19,0 \%$ \\
\hline Muy pertinente & 12 & $11,4 \%$ \\
\hline Nada pertinente & 3 & $2,9 \%$ \\
\hline Poco pertinente & 10 & $9,5 \%$ \\
\hline Total & 105 & $100,0 \%$ \\
\hline
\end{tabular}

\subsubsection{El raquitismo de la investigación en comunicación}

Pueden considerarse dos indicadores que dan cuenta de reducidas dimensiones de la investigación en comunicación: el marco temporal en el que suelen desarrollarse las investigaciones y el tamaño de los equipos.

(SCC-IEC) 1984. Miquel de Moragas. Asociación Galega de Investigadores e Investigadoras en Comunicación (AGACOM) 2000. Margarita Ledo. Sociedad Española de Periodística (SEP) 1990. Asociación de Historiadores de la Comunicación (AHC) 1992. Asociación de Investigadores en Relaciones Públicas (AIRP) 2004. Asociación Comunicación Política (ACOP) 2008. 


\section{DISERTACIONES}

\section{ESTUDIOS}

Anuario electrónico de estudios en Comunicación Social ISSN: 1856-9536

Doi: dx.doi.org/10.12804/disertaciones.09.02.2016.07

Volumen 9, Número 2 / julio-diciembre 2016

Versión PDF para imprimir desde

Figura 4. El marco metodológico: marco temporal de la investigación
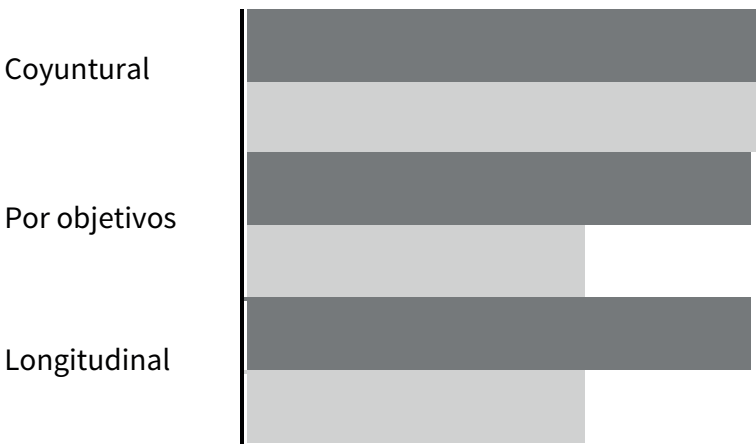

\begin{tabular}{|l|l|}
\hline Universidad & \\
\hline Empresa & \\
\hline
\end{tabular}

Si se consideran estos indicadores tanto en la investigación universitaria de la comunicación como en la investigación social y de mercado en España se puede notar que la investigación en este campo sigue siendo una actividad precaria y muy mal dotada económicamente. En efecto, los proyectos son más bien de breve recorrido dentro y fuera de la universidad (coyunturales o por objetivos en un $70 \%$ en la universidad, y fuera de ella casi en su totalidad). Por otra parte, en la figura 5 se puede observar que los equipos son de escaso tamaño ( 1 a 3 miembros, en un $50 \%$ y en menos de un $40 \%$ de 4 a 7 ).

Figura 5. Equivalencia en el tamaño de los equipos investigadores

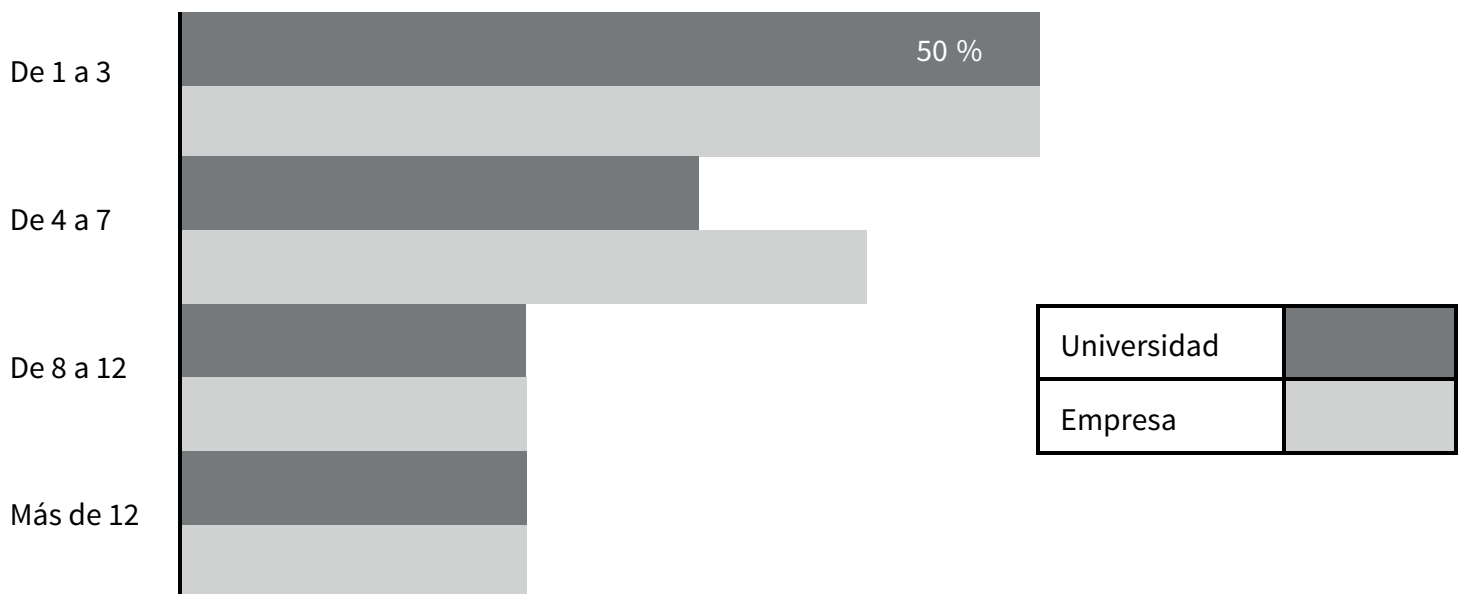

Este raquitismo de la investigación indicado por el breve recorrido temporal de la investigación y la condición liliputiense de los grupos investigadores limita la importancia, la escala o la posibilidad de crecimiento de la investigación misma y supone un gran escollo en la práctica para abordar los estudios de índole internacional (por ejemplo, europeos y latinoamericanos) que son los que devienen más necesarios por la complejidad que están adquiriendo las interconexiones comunicacionales. Hay que decir que el tamaño minúsculo de los equipos de investigación no se debe a la muestra consultada, puesto que en ella están incluidas corporaciones, consultoras e 


\section{DISERTACIONES}

ESTUDIOS

Anuario electrónico de estudios en Comunicación Social

ISSN: 1856-9536

Doi: dx.doi.org/10.12804/disertaciones.09.02.2016.07

Volumen 9, Número 2 / julio-diciembre 2016

Versión PDF para imprimir desde

http://revistas.urosario.edu.co/index.php/disertaciones

institutos de gran dimensión y tampoco, en el caso de la universidad, a los profesores consultados, investigadores principales (IP), que desarrollan precisamente la escasa investigación I+D existente en este campo de estudios.

\subsubsection{La diversidad de motores y promotores de la investigación}

De los investigadores que reconocen que su consultora, agencia o gabinete está especializada en investigación o análisis de la comunicación, la gran mayoría $(94,4 \%)$ puntualiza que sus principales clientes son las empresas. De los investigadores que reconocen que su consultora, agencia o gabinete tiene una actividad más amplia y además desarrolla estudios de comunicación, la mayoría de ellos (83,3\%) también reconoce que sus principales clientes son las empresas. ¿Qué sucede con las administraciones o instituciones públicas y la especialización de las empresas? Pues bien, los investigadores que reconocen que su organización está especializada en investigación o análisis de la comunicación, menos de la mitad (38,9\%), puntualizan que también tienen como clientes a las administraciones o instituciones públicas. No sucede lo mismo con los investigadores que indican que su organización tiene una actividad más amplia y además desarrolla estudios de comunicación, pues poco más de la mitad de los encuestados $(51,4 \%)$ reconoce que también tiene como clientes a las administraciones o instituciones públicas. En la figura 6 el lector también podrá constatar el tipo de instituciones que comprenden los principales clientes de las agencias consultoras y los gabinetes de investigación de las empresas españolas consultadas. Por orden de aparición son las siguientes: Universidades (38,4\%), Fundaciones (32,6\%), Medios de comunicación (26,9\%) y ong (11,5\%).

Figura 6. Tipos de clientes que contratan servicios de investigación de mercado

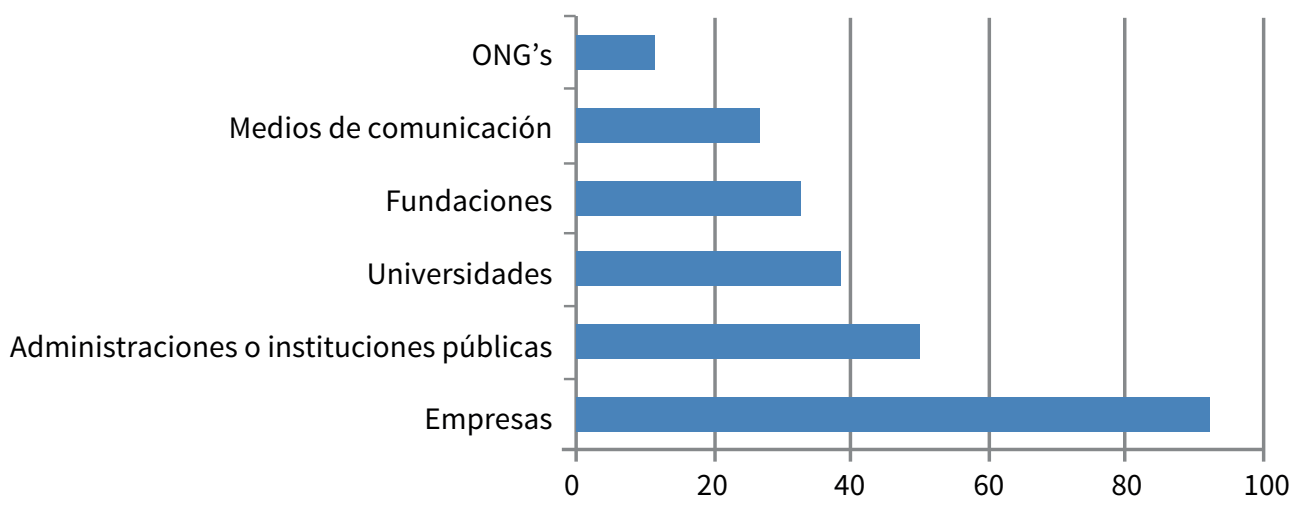

Por otra parte, cuando se les pregunta a los investigadores españoles que trabajan en los ámbitos universitarios a propósito de la financiación se puede decir (tabla 9) que 1 de cada $3(31,4 \%)$ no responde, dato que es relevante por la falta de información sobre la forma de sufragar investigaciones. No obstante, con independencia de que se trate de investigación básica o aplicada, un 43,8\% de los encuestados afirma que la financiación de sus investigaciones es pública y solo el 2,9\% dice que es privada. 


\section{DISERTACIONES}

ESTUDIOS

Anuario electrónico de estudios en Comunicación Social

ISSN: $1856-9536$

Doi: dx.doi.org/10.12804/disertaciones.09.02.2016.07

Volumen 9, Número 2 / julio-diciembre 2016

Versión PDF para imprimir desde

Tabla 8. Financiación

\begin{tabular}{|c|c|c|c|c|c|c|c|c|c|}
\hline \multicolumn{4}{|c|}{ Investigación aplicada } & \multicolumn{3}{c|}{ Investigación básica } & Sin & $\begin{array}{c}\text { No } \\
\text { responde }\end{array}$ & Total \\
\hline Mixta & Privada & Pública & $\begin{array}{c}\text { Sin } \\
\text { financiar }\end{array}$ & Mixta & Privada & Pública & $\begin{array}{c}\text { Sin } \\
\text { financiar }\end{array}$ \\
\hline 9 & 2 & 15 & 2 & 4 & 1 & 31 & 8 & 33 & 105 \\
\hline $8,6 \%$ & $1,9 \%$ & $14,3 \%$ & $1,9 \%$ & $3,8 \%$ & $1,0 \%$ & $29,5 \%$ & $7,6 \%$ & $31,4 \%$ & $100 \%$ \\
\hline
\end{tabular}

En consecuencia, el principal desajuste cuando se habla de los promotores de la investigación consiste en que prácticamente se está hablando de dos realidades distintas, es decir, mientras que los investigadores que trabajan para el mercado reconoce que son las propias empresas quienes financian su trabajos, la mayoría de los investigadores que laboran en el ámbito universitario reconoce que sus investigaciones están sufragadas por los presupuestos públicos.

\subsubsection{La relación profesional entre los investigadores de la empresa y la universidad}

En cuanto a la relación profesional de los investigadores con la universidad se puede decir que de los encuestados que responden a esta pregunta 1 de cada 3 (36,9\%) no mantiene vinculaciones con la universidad, en tanto que el resto, es decir, 2 de cada $3(63,1 \%)$ mantienen algún tipo de relación con la universidad como docente 0 investigador.

Figura 7. Relación de los investigadores con la universidad

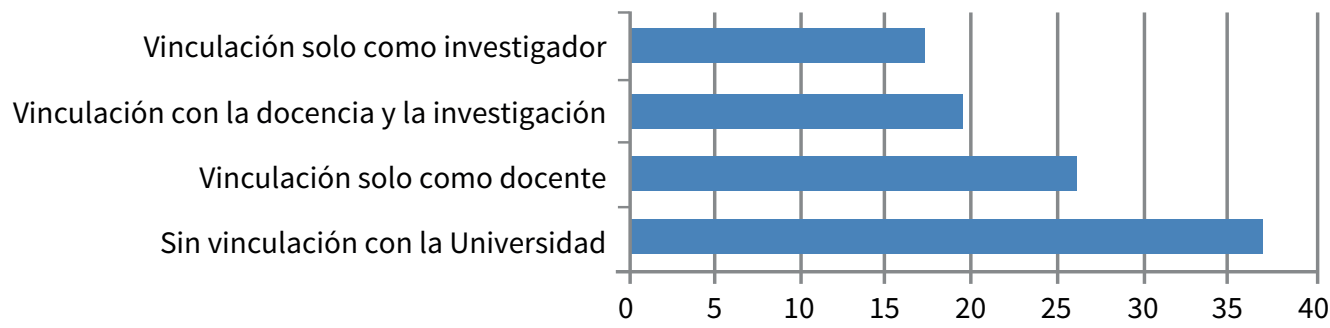

Hay que añadir que de los encuestados que no tienen ninguna vinculación con la universidad, 1 de cada 3 $(35,3 \%)$ trabaja en organizaciones especializadas en la investigación o análisis de la comunicación, mientras que 2 de cada $3(64,7 \%)$ trabaja en organizaciones que tienen una actividad más amplia y además desarrolla estudios de comunicación. Este dato demuestra la desafección existente entre la actividad investigadora que se realiza en la universidad y en las empresas especializadas en la investigación en comunicación.

Al tratar el asunto de la experiencia o formación para investigar en el campo de la comunicación hay que decir que la inmensa mayoría de los encuestados, 1 de cada 9, valora la experiencia sobre la formación de los investigadores para encarar un estudio de mercado en el campo de la comunicación. 


\section{DISERTACIONES}

Estuolos

Anuario electrónico de estudios en Comunicación Social

ISSN: $1856-9536$

Doi: dx.doi.org/10.12804/disertaciones.09.02.2016.07

Volumen 9, Número 2 / julio-diciembre 2016

Versión PDF para imprimir desde

Figura 8. Experiencia o formación para investigar

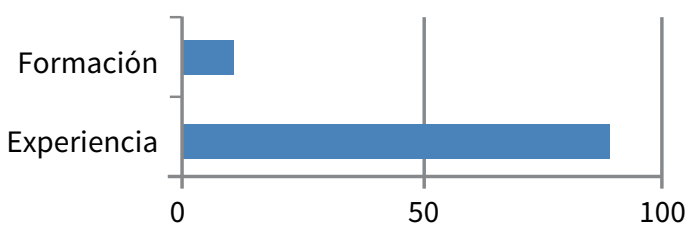

En este punto, podría encontrarse una contradicción con una pregunta anterior acerca del nivel académico, en esa cuestión casi un $85 \%$ de los encuestados subraya que este tiene mucha o bastante utilidad en la licenciatura, diplomatura o grado. Ahora bien, 3 de cada 4 de los que lo afirman valoran la experiencia $(74,5 \%)$ sobre la formación $(9,1 \%)$, mientras que el resto de encuestados no responde (16,4\%). Al respecto del tipo de formación universitaria que deben tener los miembros del equipo investigador, los que responden a esta cuestión valoran, mayoritariamente (80,5\%), la formación en las universidades púbicas, en tanto que los que avalan la formación en las universidades privadas son menos (19,4\%). Aquí hay que advertir que incluso aquellos investigadores que reconocen no tener ningún tipo de vinculación con la universidad, al tener que dirimir sobre la formación universitaria de los miembros del equipo investigador más de la mitad (58,8\%) apoya a la universidad pública, 1 de cada 5 $(23,5 \%)$ apoya a la universidad privada y el $17,6 \%$ no se pronuncia. Hay que advertir también que los encuestados que mantienen algún tipo de vinculación con la universidad prefieren de manera mayoritaria la formación pública sobre la privada en los jóvenes investigadores.

\subsubsection{Puntos fuertes y puntos débiles del investigador de la comunicación}

Si se analizan tanto las aportaciones adquiridas por los investigadores de la comunicación en la universidad como las competencias desarrolladas profesionalmente fuera de la universidad, se encuentra que:

Las principales competencias cognitivas (saber) que aporta la universidad son el rigor científico, la amplitud de enfoques, las actualizaciones teóricas, los fundamentos teóricos y epistemológicos que apoyen la visión estratégica y de conjunto, en definitiva la multidisciplinariedad. En tanto que las aptitudes desarrolladas profesionalmente a partir de estas competencias son el conocimiento solvente de los procesos de cambio social por medio de la comunicación y, sobre todo, la capacidad analítica para encuadrar los problemas sociales.

Las principales competencias procedimentales (saber hacer) que aporta la universidad son las herramientas de modelización y de análisis de la relación entre comunicación y dinámica social, además de la capacidad de utilización de metodologías cualitativas en investigación social, de comunicación o de mercado. En tanto que las aptitudes desarrolladas profesionalmente a partir de dichas competencias son las prácticas en los medios de

8 Las siguientes aseveraciones son el resultado de las repuestas a preguntas abiertas. Donde, primero, el encuestado elabora libremente su opinión, después, está tratada de forma cualitativa por el analista: de lo que se da cuenta es de la presencia frente a la ausencia, no de la frecuencia o proporción, de las categorías comprehensivas que utilizan los profesores-investigadores para referirse a su práctica profesional, siguiendo así con el propósito exploratorio y heurístico perseguido.

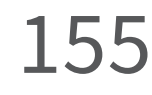




\section{DISERTACIONES}

ESTUDIOS

Anuario electrónico de estudios en Comunicación Social

ISSN: 1856-9536

Doi: dx.doi.org/10.12804/disertaciones.09.02.2016.07

Volumen 9, Número 2 / julio-diciembre 2016

Versión PDF para imprimir desde

http://revistas.urosario.edu.co/index.php/disertaciones

comunicación, el hecho de haber trabajado en investigación de mercados con clientes y en agencias de publicidad, la experiencia con las empresas de comunicación y creación de contenidos (agencias creativas, de medios, de marketing, etc.) y criterio para tomar decisiones, entendiendo criterio como ser práctico

Según los encuestados, las universidades no aportan competencias actitudinales (saber cómo ser), más bien son aptitudes desarrolladas profesionalmente como la capacidad de adaptación a distintos entornos organizacionales, la curiosidad a los detalles, la capacidad de trabajar en un equipo multicultural, los buenos dotes de comunicación, el atrevimiento y la empatía, la capacidad para desenvolverse en las relaciones públicas, el liderazgo y el trabajo en equipo. La peor parte, según los encuestados, se la llevan los profesores universitarios a quienes les hace falta pasar o tener experiencias en una empresa, suelen ser muy teóricos y lo ideal sería una experiencia mixta.

\subsection{La investigación MAPCOM}

Como se vio, el último episodio del progreso alcanzado por esta línea de sobre la Investigación en Comunicación en España es la I+D+i: El sistema de investigación en España sobre prácticas sociales de comunicación. Mapa de proyectos, grupos, líneas, objetos de estudio y métodos (CSO2013-47933-C4-1-P) 9 .

En este último estudio se constata que la investigación universitaria en Comunicación ha experimentado un crecimiento en los últimos años. Ahora bien, como puede apreciarse en la tabla 9 y en la figura 9, este aumento progresivo se produce más en el caso de las tesis doctorales que en los Proyectos del Plan Estatal de Investigación científica y técnica y de innovación, puesto que estos últimos han sufrido un severo decremento a partir de 2013, como consecuencia de los recortes presupuestarios.

Tabla 9. Investigaciones universitarias sobre Comunicación.

Tesis Doctorales y Proyectos I+D

\begin{tabular}{|l|c|c|c|c|c|c|c|c|}
\hline $\begin{array}{c}\text { Investigación } \\
\text { universitaria }\end{array}$ & $\mathbf{2 0 0 7}$ & $\mathbf{2 0 0 8}$ & $\mathbf{2 0 0 9}$ & $\mathbf{2 0 1 0}$ & $\mathbf{2 0 1 1}$ & $\mathbf{2 0 1 2}$ & $\mathbf{2 0 1 3}$ & Total \\
\hline Tesis doctorales & 73 & 167 & 180 & 235 & 248 & 278 & 377 & 1558 \\
\hline & 3 & 11 & 11 & 15 & 16 & 18 & 24 & $100 \%$ \\
\hline Proyectos I+D & 13 & 12 & 33 & 27 & 29 & 38 & 22 & 174 \\
\hline & 7 & 7 & 19 & 15 & 17 & 22 & 13 & $100 \%$ \\
\hline
\end{tabular}

9 A partir de aquí se ofrecen datos provisionales de esta investigación, que se encuentra en curso. El motivo de la presencia de estos datos en este artículo no solo es el de adelantar a los lectores los resultados que se están obteniendo en el mapa español de la investigación (en esta ocasión, se trata de datos resultantes sobre el total de proyectos I+D financiados y de un muestreo probabilístico de las tesis doctorales, en los que se ha procurado su validez externa), sino de ofrecer el último episodio, el culminante, de la línea de investigación iniciada en los estudios exploratorios anteriormente citados. 


\section{DISERTACIONES}

ESTUDIOS

Anuario electrónico de estudios en Comunicación Social

ISSN: 1856-9536

Doi: dx.doi.org/10.12804/disertaciones.09.02.2016.07

Volumen 9, Número 2 / julio-diciembre 2016

Versión PDF para imprimir desde

http://revistas.urosario.edu.co/index.php/disertaciones

Figura 9. Evolución de la Investigación en Comunicación: Tesis frente a I+D

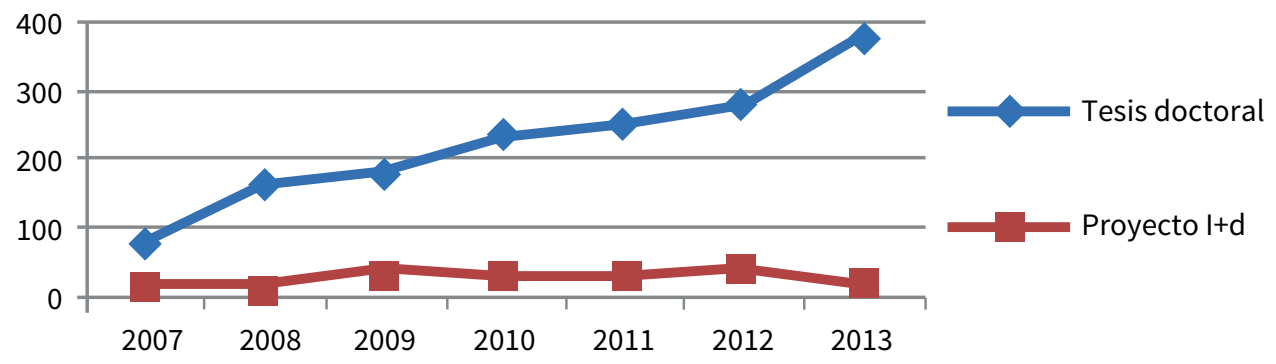

Esta investigación, en su primera fase, está configurando un repositorio de acceso abierto, en el que tengan cabida las memorias científicas de las investigaciones realizadas en España entre 2007 y 2013 así como las Tesis Doctorales leídas en el mismo periodo. Tal propósito se complementa con un análisis de contenido de ese corpus de investigaciones, en el que se analizan los objetos de estudio, los enfoques epistemológicos, los métodos y técnicas de investigación de los proyectos y de las tesis y sus líneas de investigación dominantes.

\subsubsection{La producción investigadora en comunicación según comunidades autónomas y universidades}

Sin duda, el número de tesis leídas y el de investigaciones financiadas en una universidad y en el conjunto de universidades de cada comunidad autónoma son indicadores relevantes de la producción investigadora, y lo son por su utilidad para elaborar el mapa de la investigación sobre comunicación en España.

La tabla 10 ofrece un panorama en el que destaca a la Universidad Complutense de Madrid de forma diferencial, con la mayor producción en España en número de tesis ( $25 \%$ del total de tesis doctorales) y de proyectos financiados (18\% del total de I+D). Seguida de la Universidad de Málaga (9\%), la Universidad de Sevilla (8\%) y la Universidad Autónoma de Barcelona (6\%), en cuanto a las tesis leídas. Mientras que, en relación con los proyectos financiados, la que que presenta mejor cómputo en términos absolutos, tras Madrid, es la Universidad Autónoma de Barcelona ( $11 \%$ del total de proyectos).

Tabla 10.Porcentaje de tesis doctorales y proyectos I+D según universidades con estudios en Comunicación

\begin{tabular}{|l|c|c|}
\hline \multicolumn{1}{|c|}{ Universidades con estudios en Comunicación } & $\begin{array}{c}\text { Proyectos I+D } \\
\%\end{array}$ & $\begin{array}{c}\text { Tesis doctorales } \\
\%\end{array}$ \\
\hline IE University (IEU) & 1 & 0 \\
\hline Univ. Autónoma de Barcelona (UAB) & 11 & 6 \\
\hline Univ. Cardenal Herrera CEU (UCHCEU) & 0 & 1 \\
\hline Univ. Católica de Murcia (UCAM) & 1 & 0 \\
\hline Univ. Complutense de Madrid (UCM) & 18 & 25 \\
\hline Univ. de Burgos (UB) & 1 & 0 \\
\hline
\end{tabular}

Continúa 


\section{DISERTACIONES}

ESTUDIOS

Anuario electrónico de estudios en Comunicación Social

ISSN: 1856-9536

Doi: dx.doi.org/10.12804/disertaciones.09.02.2016.07

Volumen 9, Número 2 / julio-diciembre 2016

Versión PDF para imprimir desde

http://revistas.urosario.edu.co/index.php/disertaciones

\begin{tabular}{|c|c|c|}
\hline Universidades con estudios en Comunicación & $\begin{array}{c}\text { Proyectos I+D } \\
\%\end{array}$ & $\begin{array}{c}\text { Tesis doctorales } \\
\%\end{array}$ \\
\hline Univ. Carlos III (Uс3м) & 0 & 3 \\
\hline Univ. de Castilla La Mancha (UCLM) & 1 & 0 \\
\hline Univ. de Extremadura (UEX) & 1 & 2 \\
\hline Univ. de Granada (UGR) & 0 & 1 \\
\hline Univ. de la Laguna (ULL) & 0 & 4 \\
\hline Univ. de las Islas Baleares (UIB) & 2 & 0 \\
\hline Univ. de Málaga (UMA) & 1 & 9 \\
\hline Univ. de Murcia (uм) & 2 & 0 \\
\hline Univ. de Navarra (UNAv) & 0 & 4 \\
\hline Univ. de Sevilla (us) & 2 & 8 \\
\hline Univ. de Valencia (uv) & 4 & 2 \\
\hline Univ. de Valladolid (UVA) & 2 & 1 \\
\hline Univ. de Vigo (uvigo) & 0 & 4 \\
\hline Univ. del País Vasco (UPV/EHU) & 7 & 4 \\
\hline Univ. Jaume I (UנI) & 3 & 2 \\
\hline Univ. Miguel Hernández (чмн) & 3 & 1 \\
\hline Univ. Politécnica Valencia (UPM) & 3 & 1 \\
\hline Univ. Pontifica de Salamanca (UPSA) & 0 & 1 \\
\hline Univ. Pompeu Fabra (UPF) & 6 & 3 \\
\hline Univ. Ramon Llull (URL) & 4 & 3 \\
\hline Univ. Rey Juan Carlos (URJC) & 10 & 3 \\
\hline Univ. Rovira Virgili (URV) & 8 & 1 \\
\hline Univ. San Pablo CEU (USPCEU) & 0 & 3 \\
\hline Univ. Santiago de Compostela (usc) & 5 & 5 \\
\hline Univ. de Salamanca (USAL) & 1 & 2 \\
\hline Univ. de Lleida (UdL) & 3 & 0 \\
\hline Univ. de Alicante (UA) & 1 & 0 \\
\hline Univ. Internacional de Catalunya (UIc) & 0 & 0 \\
\hline Univ. Oberta de Catalunya (uoc) & 0 & 0 \\
\hline \multirow[t]{2}{*}{ Univ. de Coruña (UDC) } & 0 & 0 \\
\hline & $\begin{array}{c}100 \% \\
I+D\end{array}$ & $\begin{array}{l}100 \% \\
\text { Tesis }\end{array}$ \\
\hline
\end{tabular}

Nota: Al menos estudios de Grado o Licenciatura (datos provisionales, redondeo).

En la tabla 11 y en la figura 10 se observa que la financiación de proyectos I+D en relación con la producción de investigaciones de tesis ofrece valores de distribución desigual, es decir, no estando balanceada según comunidades autónomas. Así, cabe observar cómo algunas comunidades se ven perjudicadas y otras beneficiadas por esta 


\section{DISERTACIONES}

ESTUDIOS

Anuario electrónico de estudios en Comunicación Social

ISSN: 1856-9536

Doi: dx.doi.org/10.12804/disertaciones.09.02.2016.07

Volumen 9, Número 2 / julio-diciembre 2016

Versión PDF para imprimir desde

http://revistas.urosario.edu.co/index.php/disertaciones

ratio. La desproporción más evidente, si se tienen en cuenta el número de proyectos que reciben financiación por el Plan Estatal de Investigación científica y técnica y de innovación, aparece con la Comunidad de Catalunya, que es beneficiada más que cualquier otra por estas concesiones, aunque seguida de cerca por la Comunidad Valenciana, siendo el País Vasco y las Baleares los siguientes. Al otro extremo, cabe encontrar a la comunidad más perjudicada en Andalucía, cuya desproporción de producción de tesis y de número de asignaciones de financiación es inversamente proporcional a la obtenida por Catalunya. Entre las comunidades que también son agraviadas se encuentran Madrid (-4 puntos) y Galicia (-5 puntos), ambas distanciadas de la media de esta distribución (+8), el fiel de esta balanza entre las magnitudes comparadas, fiel al que se aproxima más la Comunidad del País Vasco (+3).

Tabla 11. Tesis doctorales y proyectos I+D sobre comunicación según comunidades autónomas con estos estudios universitarios

\begin{tabular}{|c|c|c|c|}
\hline $\begin{array}{l}\text { Universidades con estudios } \\
\text { en Comunicación }\end{array}$ & $\begin{array}{l}\text { Proyectos I+D } \\
\%\end{array}$ & $\begin{array}{c}\text { Tesis } \\
\text { doctorales } \\
\%\end{array}$ & $\begin{array}{l}\text { Ratio entre } \\
\text { I+D y tesis } \\
\text { doctorales }\end{array}$ \\
\hline Andalucía & 3 & 19 & -16 \\
\hline Aragón & 0 & 0 & 0 \\
\hline Asturias (P. de) & 0 & 0 & 0 \\
\hline Baleares (Illes) & 2 & 0 & +2 \\
\hline Canarias & 0 & 4 & -4 \\
\hline Cantabria & 0 & 0 & 0 \\
\hline Castilla - La Mancha & 1 & 0 & +1 \\
\hline Castilla y León & 5 & 3 & +2 \\
\hline Catalunya & 31 & 14 & +17 \\
\hline Extremadura & 1 & 2 & -1 \\
\hline Galicia & 5 & 10 & -5 \\
\hline Madrid (C. de) & 27 & 31 & -4 \\
\hline Murcia (Región de) & 2 & 1 & +1 \\
\hline Navarra & 0 & 4 & -4 \\
\hline País Vasco & 7 & 4 & +3 \\
\hline Rioja (La) & 0 & 0 & 0 \\
\hline Valenciana (C.) & 16 & 8 & +16 \\
\hline Ceuta & 0 & 0 & 0 \\
\hline \multirow[t]{2}{*}{ Melilla } & 0 & 0 & 0 \\
\hline & $\begin{array}{c}100 \% \\
\text { I+D }\end{array}$ & $\begin{array}{c}100 \% \\
\text { Tesis }\end{array}$ & $\begin{array}{l}+8 \% \\
\text { media }\end{array}$ \\
\hline
\end{tabular}

Nota: (datos provisionales, redondeo). 


\section{DISERTACIONES}

ESTUDIOS

Anuario electrónico de estudios en Comunicación Social

ISSN: $1856-9536$

Doi: dx.doi.org/10.12804/disertaciones.09.02.2016.07

Volumen 9 , Número 2 / julio-diciembre 2016

Versión PDF para imprimir desde

http://revistas.urosario.edu.co/index.php/disertaciones

Figura 10. Ratio entre tesis doctorales y proyectos I+D sobre comunicación según Comunidades Autónomas con estos estudios universitarios

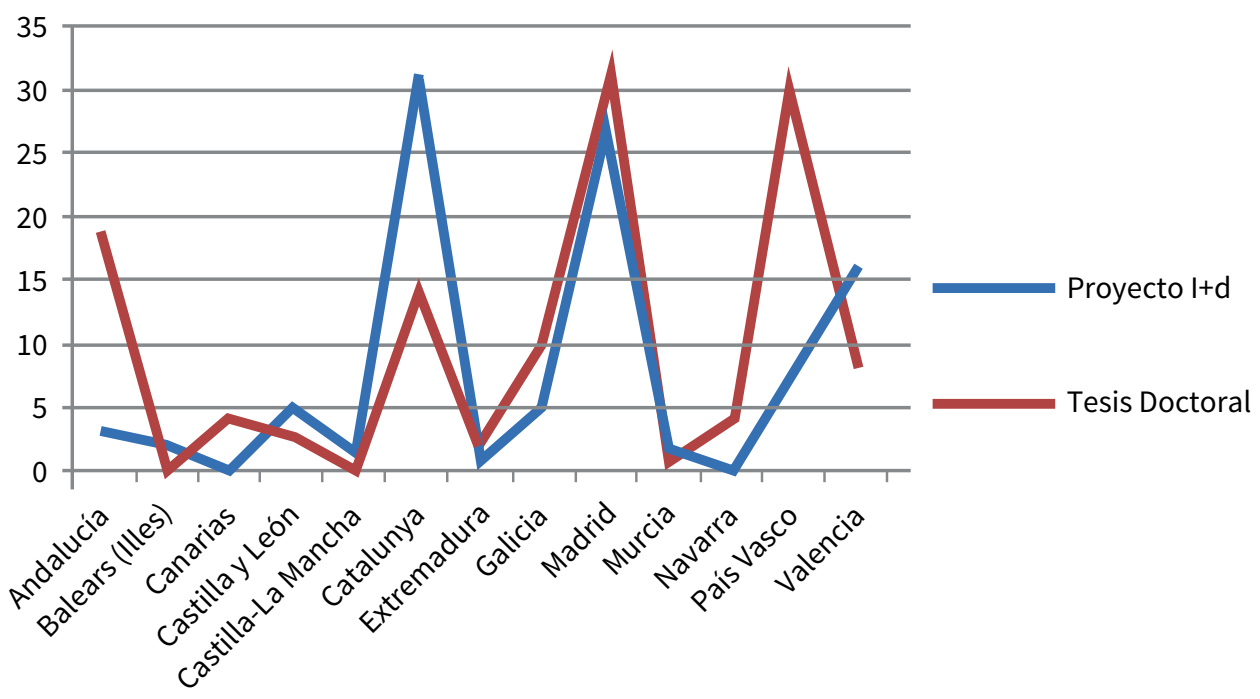

Nota: (datos provisionales, redondeo)

\section{Discusión}

Como propuesta de debate, queda aquí un planteamiento a futuro que tiene por función intentar superar la situación que proporcionan los datos obtenidos sobre el estado de la investigación en el campo. Se trata de plantear la relación constitutiva con las praxis investigadoras del estatus científico de las Ciencias de la Comunicación y el papel guía que ha de protagonizar la universidad por medio de la innovación y creación que proporciona la investigación comunicacional para la Sociedad del conocimiento.

En el desarrollo de la línea de investigación que aquí se ha presentado, se ha querido diagnosticar el estado de la cuestión, fijando en primer lugar, en el hipotético desajuste existente entre el currículo formativo y la investigación en Comunicación. Esta indagación ofrecía una constatación de que el cambio en las aulas no se estaba produciendo al mismo ritmo que el cambio en los objetos comunicaciones de estudio. Las explicaciones de este desajuste probablemente tienen que ver con razones estructurales que afectan más a la docencia de títulos y materias que a la investigación de temas de actualidad. Es decir, en la docencia universitaria todavía rige una estructura organizativa departamental, que se traduce en un panorama de enseñanzas insuficientemente renovadas, a veces anquilosadas, mientras que los grupos de investigación gozan de una independencia y un desarrollo basados más bien en la evaluación de los resultados y más ajustado en la elección de sus objetos de estudio a las exigencias de una sociedad que, sobre todo en el sector de la comunicación se halla sometida a una dinámica de cambios muy acelerada. Otra explicación complementaria de este desajuste es que los objetos de estudio más relacionados con los procesos de cambios en la sociedad de la información se seleccionaban primero para la 


\section{DISERTACIONES}

ESTUDIOS

Anuario electrónico de estudios en Comunicación Social

ISSN: 1856-9536

Doi: dx.doi.org/10.12804/disertaciones.09.02.2016.07

Volumen 9, Número 2 / julio-diciembre 2016

Versión PDF para imprimir desde

investigación y, más tarde, con los resultados del análisis, para la docencia universitaria. En cualquier caso, se podría pensar que los temas deberían articularse acompasadamente en el mismo proceso académico -al menos en el Tercer Ciclo, en los Másteres-, por ejemplo, integrándolos en la docencia mientras dichos temas se están abordando también en la investigación, aun cuando la investigación misma no sea objeto de la docencia .

Como hemos visto, también existe un desajuste entre la investigación social y de mercado y la investigación universitaria. Los investigadores de la primera reclaman los fundamentos teóricos y metodológicos que solo posee la Academia, mientras la universidad se encuentra aislada de la sociedad y del mercado, reclamando reconocimiento social y financiamiento privado de muchas de sus actividades de investigación.

Un ejemplo de este desajuste se vislumbra en la desvinculación entre los investigadores de la comunicación de ambos sectores. Sin duda, para superar la brecha abierta por esta desvinculación habrá que realizar propuestas en las que sea posible una articulación de la investigación en la sociedad globalizada o en sus objetivos, al menos en sus prácticas. Esto no significa que se esté reclamando una privatización de la universidad, sino una apertura de la universidad pública a los fenómenos sociales. Se debería entonar el mea culpa, pues los investigadores universitarios de la comunicación deben plantearse que la configuración de un paradigma de las Ciencias de la Comunicación no es solo una cuestión de índole epistemológica sino sobre todo praxeológica y consiste, en gran medida, en ser capaz de responder, al menos con la práctica investigadora en Comunicación, a la exigencia demandada por la coyuntura histórica de participar como un agente social en los cambios inherentes a la globalización. Es decir, lo que todavía está por ocurrir en el amplio sector de la Comunicación -y es un reto pendiente para los que se precian en llamarse comunicólogos-, es que desde la universidad deben liderase ciertos procesos de generación - de la teoría a la ingeniería de las TIC's- de la innovación comunicacional, como principal instancia creadora, gestora y transmisora del conocimiento en la sociedad de la información. Este es el nuevo papel que se reclama de las Ciencias de la comunicación: la universidad podría y debería constituirse en el artífice y/o abanderado de ese cambio en las prácticas y los procesos comunicacionales, sobre los que hasta ahora se ha aventurado a investigar y, en menor medida, a formar.

Es decir, se hace cada vez más irrenunciable para la universidad en general, y para las Ciencias de la Comunicación en particular - además de su tradicional formación teórica y metodológica- adoptar ese nuevo papel, donde a la actuación directa de exploración y análisis se sume la prospección e intervención estratégica sobre los fenómenos comunicacionales en tiempo real, y no solo de manera diferida.

Así pues, quedan abiertos muchos temas para el debate. Por una parte, las instituciones sociales y las organizaciones privadas demandan investigación comunicacional y legitimidad corporativa creciente sobre ciertos fenómenos comunicacionales que les afectan o protagonizan, de modo que hay que seguir investigando en torno a la mejor forma de conectar las organizaciones sociales a la investigación universitaria en comunicación. Por otra parte, es inevitable que la universidad ejerza un liderazgo sobre determinados procesos de generación de la innovación comunicacional en la sociedad y en el sector empresarial. No hay que desdeñar su ingente potencial investigador material y humano, además de ser la principal gestora y transmisora del conocimiento en la sociedad de la información. 


\section{DISERTACIONES}

Estuolos

Anuario electrónico de estudios en Comunicación Social

ISSN: $1856-9536$

Doi: dx.doi.org/10.12804/disertaciones.09.02.2016.07

Volumen 9, Número 2 / julio-diciembre 2016

Versión PDF para imprimir desde

\section{Referencias}

1. Costa, J. (2001). Imagen corporativa en el siglo xxı. Barcelona: Ediciones La Crujía.

2. Currás, R. (2010). Identidad e imagen corporativas: revisión conceptual e interrelación. Teoría y Praxis, 7, 9-34. Recuperado de http://www.teoriaypraxis.uqroo.mx/doctos/Numero7/Curras.pdf

3. Gaitán, J. A. (2010). Desarrollos teóricos y metodológicos de investigación en epistemología de la comunicación. Recuperado de http://www.aeic2010malaga.org/upload/ok/176.pdf

4. González, J. (2002). Identidad visual corporativa: la imagen de nuestro tiempo. Madrid: Síntesis.

5. Hernández, A. (2002). Planificar la comunicación. Revista Latina de Comunicación Social, 48. Recuperado de http://www.ull.es/publicaciones/latina/2002/latina48marzo/4812ajhernandez.htm

6. Lozano, C., \& Gaitán, J. A. (2011). Dedicación a la investigación y a la docencia universitaria en comunicación: compatibilidad y perfiles en España, Europa y América Latina. En J. L. Piñuel, C. Lozano, \& A. García. Investigar la Comunicación en España (pp. 587-595). Fuenlabrada: Facultad de Ciencias de la Comunicación. Universidad Rey Juan Carlos.

7. Lozano, C., \& Vicente, M. (2010). La enseñanza universitaria de las Teorías de la Comunicación en Europa y América Latina. Revista Latina de Comunicación Social, 65, 255-265. Recuperado de http://www.revistalatinacs.org/10/art2/898_URJC/20_Lozano.html

8. Ministerio de Educación, Cultura y Deporte (2015). Datos y Cifras del Sistema Universitario Español. Curso 2014/2015. Secretaría General de Universidades. Madrid: Secretaría General Técnica. Subdirección General de Documentación y Publicación.

9. Orozco, J. A., \& Ferré C. (2012). Los índices de reputación corporativa y su aplicación en las empresas de comunicación. Ponencia presentada en el III Congreso Asociación Española de Investigación de la Comunicación, Tarragona. Recuperado de http://www.aeic2012tarragona.org/comunicacions_cd/ok/95.pdf

10. Piñuel, J. L. (2009). La comunicación como objeto científico de estudio, como campo de análisis y como disciplina científica, Contratexto Digital, 18

11. Piñuel, J. L. (2011). La docencia y la investigación universitarias en torno a la Comunicación como objeto de estudio en Europa y América Latina +Teaching and Research on Communication as an object of study in European and Latin-American universities. San Cristóbal de La Laguna, Tenerife: Revista Latina de Comunicación Social.

12. Piñuel, J. L. Lozano, C., \& García, A. (2011). Investigar la Comunicación en España. Fuenlabrada: Facultad de Ciencias de la Comunicación. Universidad Rey Juan Carlos.

13. Vicente-Mariño, M., González-Hortigüela, T., \& Pacheco-Rueda, M. (Coords). (2013). Investigar la comunicación hoy: revisión de políticas científicas y aportaciones metodológicas. Actas del II Congreso Nacional sobre Metodología de la Investigación en Comunicación y del Simposio Internacional sobre Política Científica en Comunicación (Segovia, 2-3 de mayo de 2013). 